This item was submitted to Loughborough's Research Repository by the author.

Items in Figshare are protected by copyright, with all rights reserved, unless otherwise indicated.

\title{
What is metropolitan planning and governance for?
}

PLEASE CITE THE PUBLISHED VERSION

https://link.springer.com/chapter/10.1007/978-3-030-25632-6_14

PUBLISHER

Springer

VERSION

AM (Accepted Manuscript)

LICENCE

CC BY-NC-ND 4.0

REPOSITORY RECORD

Galland, Daniel, John Harrison, and Mark Tewdwr-Jones. 2019. "What Is Metropolitan Planning and Governance For?". figshare. https://hdl.handle.net/2134/37876. 


\title{
14. What is Metropolitan Planning and Governance for?
}

\author{
Daniel Galland, John Harrison and Mark Tewdwr-Jones
}

\begin{abstract}
This concluding chapter argues for a new role of planning in shaping metropolitan futures and reflects on the value of the book's thematic-temporalphronetic (TTP) framework - a meso-level approach to better understand the dynamics of contemporary metropolitan change. We begin by revealing the extent to which institutions, policies, spatial imaginaries and planning are influencing metropolitan development through a synthesis of the key outcomes emanating from the totality of the book contributions. The chapter then returns to the TTP framework to reflect on its tripartite rationale as well as its significance to international comparative research. Set against this context, the chapter then identifies four sets of issues that seem highly relevant to both shape future styles of governance and planning, and provide metropolitan regions with modes of working that could make a difference. We finally conclude with three open propositions relating to thematic, temporal and phronetic priorities for future research targeting the planning and governance of metropolitan regions.
\end{abstract}

\subsection{How Institutions, Policies, Spatial Imaginaries and Planning are Influencing Metropolitan Development}

Metropolitan regions are widely considered to be an ideal scale for policy intervention in the twenty-first century. Yet, what is also clear is that metropolitan regions are increasingly reliant on inadequate urban-economic infrastructures, as well as fragmented governance and planning arrangements. These mismatches and coordination issues are intrinsically at the heart of the metropolitan question because they represent the starting point for cooperation in many contexts and yet they remain unsolved issues. Alongside this, the emergence of new spatial concepts means the metropolitan region cannot be regarded as the a priori spatial scale, but must be considered increasingly as one among many spatial concepts. These factors pose fundamental questions about what is metropolitan planning and governance actually good for?

Our aim with this book has been to move the debate forward in two ways. Firstly, the contributions reveal the extent to which institutions, policies, spatial 
imaginaries and planning are influencing metropolitan development. From here authors have offered a more critical take on 'how can' and 'how should' institutions, policies, spatial imaginaries and planning affect metropolitan change in a more progressive way. Secondly, the book offers a new way of approaching how we research metropolitan regions through the TTP (thematic-temporal-phronetic) framework. In what follows, we reflect on the value of these two approaches and show how they can extend much further than the immediate focus of this book. In the final part we explore the role of planning in metropolitan futures.

\section{Institutions}

There is no denying that institutions - both formal and formal - matter for affecting metropolitan change but their capacity is inherently uneven across time and space. Temporally, our periodising of metropolitan regional development identifies three key periods of institutional change:

- Government (1950s-70s): this was the dominant approach in the era of spatial Keynesianism. A top-down model rooted in state-territoriality where the key actors were state institutions (central government, local government, metropolitan government).

- Governance (1970s-2000s): commonly divided into two phases (1970s-80s New Localism; 1990-2000s New Regionalism) this emerged to become the dominant approach in the era of neoliberal restructuring. It saw evolution from the governmental approach of spatial Keynesianism to include other actors most notably business and private sector. Institutions became more entrepreneurial, symbolised in the rise of public-private partnerships.

- Circumventing government and governance (2010-): we now see other actors attempting to disrupt or circumvent traditional modes of government and governance institutions and institutional frameworks to influence metropolitan policy and affect metropolitan change. Examples include major philanthropic organisations, consultancy firms and celebrated experts which work to complement and/or compete with existing institutional forms, making the metropolitan landscape increasingly complex.

It is in this latest phase of institutional thinking, metropolitan spaces are increasingly viewed as depoliticised spaces of consensual, post-political policymaking following the erosion of urban-governmental capacities and the exposure of cities and regions to market-oriented forms of late-neoliberal planning and governance. This is critical for our understanding of institutions and their capacity to affect metropolitan change because, on the one hand, institutional change is trumpeted as doing exactly this (Barber 2013, Katz and Bradley 2013, Oosterlynck et al. 2019) and yet, on the other hand, the political-economic conditions run counter 
to this (Davidson and Ward 2018, Etherington and Jones 2016, Gross et al. 2019, Jones 2019, Peck 2017a/b).

The latest round of institutional reforms includes the promotion of (metropolitan) mayors, which in several European - as well as some non-European - countries are intimately tied to other institutional arrangements such as urban contractual policies. These new forms of institutional governance reinforce the emphasis placed in this book of going beyond questions that ask 'what' these arrangements are and 'where' they are emerging, to dig deeper into understanding 'who' is enabling this, 'how' and 'why' they are doing it, and ultimately, 'what is at stake'? There are prominent examples emerging where the institutionalisation of metropolitan regions through processes of devolution are becoming vehicles for implementing cuts to social welfare, public services and delivering austerity (Etherington and Jones, 2018). More pertinently, at the heart of many metropolitan region initiatives is an underlying tension between the triumphal rhetoric of a devolutionfuelled growth-agenda running counter to the murky reality of a wider state project of austerity and fiscal constraint. How this plays out on the ground is that metropolitan regions are left with a larger slice of a smaller cake. All of which means that this, as well as other recent developments, urgently require consideration as to whether metropolitan institutional reforms are actually smokescreens for other agendas (e.g. devolving austerity).

What thinking like this requires is further analysis of the type identified in this book, which pinpoints a series of critical questions. To get to these more fundamental and deep-rooted questions we must look beyond the metropolitan institution itself to ask: if this institution is the answer then what is the question? This is key because institutions are not the end point, they are the means to another end. Institutions are only the mechanism, a process of change but one which happens in order to change and impact something, someone or somewhere else. Moreover, in present day conditions, do we really need/want metropolitan institutions? If so, what do these institutions look like? Are there institutional solutions to the fundamental challenges facing metropolitan regions going forward? Realistically, can we balance institutional agility with issues of legitimacy and accountability in a neoliberal political-economy?

\section{Policies and Ideas}

Policies and policy ideas hold an intrinsic potential to influence metropolitan change. However, both policy implementation and its impact on metropolitan change are largely contingent on metropolitan institutions, i.e. the more the latter are prone to shift over time the less likely policies are able to influence change in metropolitan regions. The periodisation of contemporary processes of metropolitan change pertaining to policies depicts a tendency for institutional reforms to remain constant irrespective of national contexts. Institutional reforms are widely 
justified on the basis of decision makers' discourses (e.g. the pursuit of economies of scale) concerning the need to continuously subject institutions to changing conditions. This situation has become the common denominator of (metropolitan) institutions since the crisis of Keynesian welfarist national states and their subsequent transition towards governance regimes in times of neoliberal readjustments. The same reformist tendency associated with institutions has prevailed over the course of the twenty-first century. Endorsed by rationales of administrative efficiency, decentralisation and economies of scale, the promotion of (local, metropolitan and regional) structural reforms has long been politically justified in diverse national contexts through the widely generic and accepted discourse of promoting competitiveness in today's increasingly globalised and financialised world.

The disjunctural dynamics emerging from constant institutional reforms and unrealised metropolitan policies and ideas generate a phenomenon of 'arrhythmia'. Characterised by differential temporal patterns, this arrhythmic state oftentimes translates into a lack of policy implementation unless ad hoc metropolitan policy streams, alongside an unusual condition of institutional steadiness at the metropolitan scale, can generate a conjuncture that unleashes the intrinsic capacity of policies to shape metropolitan regions.

An overarching 'policy void' is arguably generated by the above disjuncture of and resulting arrhythmia between institutions and policies. This void generates a metropolitan policy window which has been increasingly filled in by universalised, one-size-fits-all metropolitan policies (e.g. OECD 2015a/b). This filling-in process has been increasingly steered by international organisations (e.g. World Bank, OECD, UN Habitat and Cities Alliance), non-profit public policy organisations (e.g. Brookings), universities offering executive masters programmes and transnational municipal networks (TMNs), all of which act as 'certifying agencies' imposing templates comprised of 'good practices' and recommendations founded on economic growth and competitiveness logics. This seemingly one-size-fits-all approach to metropolitan policy is eloquently facilitated, mobilised and fostered by travelling policy gurus who play a key role as policy champions.

Exhibiting only limited guidance to real, localised metropolitan issues, these universalised, supranational and international policy ideas are actively used by metropolitan elites as windows of opportunity to promote their own models and concepts. Simultaneously, the same ideas arrive to the ears of thousands of urban and regional planners who act as their recipients within their own national planning contexts and cultures. However, the reality is that both international organisations as well as policy gurus frequently impose largely unreflective frames that focus on what they regard as competitiveness-oriented metropolitan successes (i.e. which they portray based on comparing metropolitan regions attaining economic growth goals versus those failing to do so). The issue of accessibility to such latest metropolitan successes is normally done via membership and payment, which leads to issues of exclusion. For instance, in the case of 'Metropolis', an international association of major metropolises that acts as a connecting hub to share ex- 
pertise on metropolitan governance, the implication is that only a selective group of 'member' metropolitan regions gets to 'upload' ad hoc metropolitan policies and ideas. The same dynamics apply for policy downloading, which is only available to member metropolitan regions but not others. the spread of certain policies and ideas to some metropolitan regions but not others.

The key implication is that the above disjunctural processes alongside the fact that policies and policy ideas remain largely controlled by a few corporate entities and policy communities (i.e. gurus, philanthropies, city networks, consultants) create a stranglehold (Stone 2008, Peck 2016). The question of who has control over which policy ideas get promoted and which do not becomes more critical than ever before. With 'travelling best practices' prioritising economic development, marketing strategies and infrastructure investments, how is the real localised problematique associated with any metropolitan region to be accounted for? Are best practices concerning public services, public transportation infrastructure and land-use planning travelling at the same pace? Who deals with situated and, in most world contexts, exacerbating socio-spatial issues of intra-urban and interurban inequality and differentiation? In times where urbanisation stands out as the key global driving force shaping metropolitan regions, stakes are only meant to get higher. In an urbanising world characterised by metropolitan governance accretion, this begs the question of how metropolitan policy is to be imagined and designed and whether, how and where policy does hold potential to shape metropolitan futures, particularly in Global South contexts.

The challenge then becomes how to avoid defaulting off-the-shelf international organisation policies and ideas, particularly in the current climate of increasing discussions about South-North and South-South learning (Ammann and Förster 2019, Fiddian-Qasmiyeh and Daley 2019, Tomlinson and Harrison 2019). This calls for 'learning to unlearn' - whereby the 'situatedness' of policy ideas should acknowledge the limitations of universalised metropolitan policy assumptions (Lawhon et al. 2016). In policy research, it similarly leads to thinking about alternative conceptualisations that consider difference of new policy epistemologies to better understand the diversity of metropolitan contexts (Galland and Elinbaum 2018, Kovacic 2019, Watson 2016).

\section{Spatial Imaginaries}

Spatial imaginaries are important for metropolitan change and development, but their direct impact is minimal. The role of spatial imaginaries lay in discursively framing metropolitan development, oftentimes being used to convince and justify certain actions. Whereas traditionally spatial imaginaries - in the form of maps - effectively were 'the plan', they are now increasingly part of the plan or in many cases, there is not even a plan to speak of. Put simply, spatial imaginaries have assumed the role of being a way of imaging space, designed to convey a par- 
ticular message - be it to promote a certain form of metropolitan development, to make a case for institutionalising a particular idea of what the metropolitan region is, to attract and prioritise capital investment towards certain locations and so on. Just as with institutions, spatial imaginaries are not an end point. They are part of a process designed to affect metropolitan change. In the case of spatial imaginaries, they are often the starting point for those conversations to take place, a way of capturing attention and provoking discussion.

Key to understanding the impact of imaginaries on metropolitan regions is to recognise how they are mobilised to defend or advance certain essential interests. Most important is that as the metropolitan paradigm has developed apace, more and more actors having a stake the planning and governance of metropolitan regions has resulted in more complex, that is, overlapping and competing visions for the metropolitan region and metropolitan regional development. Add to this the increasingly multiscalar (i.e. the conceptual stretching of the metropolitan region concept to refer to the very local scale through to the mega-urban scale in different space-times), multispatial (be it underpinned by networked, territorial, placebased, scalar conceptions of sociospatial relations) and multidimensional (emerging from a geoeconomic, geopolitical or geohistorical logic) approaches to considering the metropolitan region, and one starts to seeing the difficulty in mobilising a singular approach to imagining metropolitan regions and how they are mobilised to affect metropolitan change.

This hyper-complexity of contemporary metropolitan regions, reflected in their simplified yet still complex spatial imaginaries, is arguably the symptom that points to a series of more fundamental challenges when observing emergent trends in processes of large-scale metropolitan expansion. Arguably most significant is how weakly institutionalized many new metropolitan imaginaries are. While a space might be recognised as a metropolitan region and have this label, this does not mean it is meaningful in any significant way. Weakly institutionalised metropolitan regions create detachment from the actual planning and governance of metropolitan regions, and this in turn can lead to even less citizen engagement. Allied to, and irrespective of this, the trend towards a smaller number of increasingly large metropolitan regions has led critics to argue: "We can hardly plan at the regional scale, let alone for megaregions" (Wheeler 2015, p.99, cf. Friedmann and Sorensen 2019). And where to go next when the spatial imaginary becomes transnational corridors or planetary urbanisation? Or, as the example of Germany illustrates (Harrison et al. 2020), we can already see a 'planetary metropolitanisation' in many representations of metropolitan regions because nowhere can now be considered as not being metropolitan (see also OECD, 2015a).

Looking ahead, two emergent trends appear particularly important in this regard. The first relates to the advent of live stream data and real-time modelling. As this becomes more integrated into all parts of society, this offers a new way of imagining metropolitan regions. Perhaps more significant, looking back at how the emergence of depoliticised spaces of consensual, post-political policy-making has seen citizens increasingly detached from metropolitan place-making, theoretically 
they can now access this information and the resultant imaginaries anytime, anywhere, so long as they have a broadband connection. The second is more conceptual and requires us to ask: are we looking in the right places? Urbanisation over the next generation is going to take place predominantly in the Global South, yet we still obsess about Western European and North American metropolitan spatial imaginaries. And even within this focus, academic research and policy elites have been selectively channelling their attention disproportionately towards major urban regions. In both cases we are witnessing the emergence of a strong counternarrative calling our attention to those places which have always mattered, but it has been decided do not matter because most of the focus has been on the perceived growth of major agglomerations.

\section{Planning Approaches}

From inception, a series of historical features have characterised planning in its role to cater to metropolitan development. Amongst these attributes stand out the endeavour of planning to achieve place-based distinctiveness resting upon local needs, its efforts to embed metropolitan change within democratic mandates and its attempt to consolidate a future vision of place. In the era of Spatial Keynesianism, planning for metropolitan change strove to advance the means to deal with spatial interrelationships in the long term while adopting rational comprehensive and systems' styles to harness data and flows of information. At the same time, planning sought to become an advocacy domain giving others a voice under politically complex processes of change.

These hallmarks, however, have certainly proven to exert varying degrees of influence on metropolitan development and, lately, it appears that the role of planning has neither been significant nor fit for purpose within most national contexts. While the longue durée shows us how metropolitan planning typically relied on elected government representatives, a public service ethic in pursuit of the greater good and a strategic place-with-plan approach, the more recent decades of neoliberal influence exhibit a mix of government, governance and govern-less forms, where the primacy of the global market causes that city regions become more prevalent than nation states (Borraz and Le Gales, 2010). Under this reality, the planning domain has witnessed the rise of unprecedented external driving forces that supersede it - forces which directly or indirectly play a more prominent role in shaping metropolitan change. Indeed, external forces such as globalisation and financialisation out-trump planning, making it only possible for the latter to cope with them through an increasing use of ad hoc incremental and project-led styles that are characteristically short-termed and siloed.

Struggling to subsist under the ever-increasing influence and pressure of these forces on metropolitan growth and development, the planning domain partly seeks nowadays to rely more on the adoption of informal tools, instruments and policies. 
The issue of formal versus informal planning has become more widespread, thus setting a dichotomy between orthodox and incrementally-agile forms of planning. In so doing, the domain has adopted an oftentimes confusing range of styles characterised by the continual alignment between actors, a temporal fixity in space linked to highly volatile global and national contexts, and a spatial fixity in time focused on individual projects. These emerging conditions of planning are not exempt from internal dilemmas: should planning continue to have long-term, bounded and legitimate plans under the pressure for short term agility? How should planning cope with the issue of 'copy-pasting' policies and ideas, habitually unreflectively, from different territorial and socio-political realities.

The above emergent trends and dilemmas beg the question of how planning should reinvent itself to exert more influence on metropolitan growth and development in a reality where the domain is clearly losing to other drivers of metropolitanisation as well as other policy sectors. Planning has largely failed to comply with its original hallmarks, partly as a consequence of the domain's split into particular activities and partly due to the states' lack of ability to innovate, which is coupled with the fragmentation of institutions of change by sector, space, policy and intervention. Contrary to its indigenous condition of permanence as a state institution, the present requirement for planning to be a mechanism of convenience to align and coordinate between agencies often means that planning fails to endure. These series of implications call back to re-focus on basic yet fundamental questions: What should be the role of planning in the metropolitan century? Who is planning for and whose interests should it defend in contexts where there is a loss of the institutional memory that shaped spatial change? Should planning adopt an advocacy role in pursuit of more democratic values? Does planning still need the plan?

\subsection{Rethinking Metropolitan Regions: Do Institutions, Policies, Spatial Imaginaries and Planning Really Matter for Metropolitan Development?}

The central argument of this book is that there is an important middle-ground between macro-level, abstract-conceptual analysis of metropolitan regions which seeks simplicity through theoretical generality across time and space, and microlevel, systematic comparative analysis which identifies difference across diverse empirical cases. Moreover, we propose a new way of analysing metropolitan regions through what we refer to as the TTP (thematic-temporal-phronetic) framework (Galland and Harrison, 2020). In this section we return to the TTP framework, exploring its potential as an analytical approach for better understanding the dynamics of metropolitan change.

The rationale for the three dimensions of the TTP framework is as follows: 
- Thematic: focusing on any single theme only provides a partial, onedimensional, reading of metropolitan regions. A thematic approach emphasises plurality and reveals the interconnections between the multiple drivers of metropolitan change.

- Temporal: focusing on present-day episodes of contemporary metropolitan change often overlooks striking similarities from different historical contexts. A temporal approach recognises how we have arrived here to better understand what is currently happening and plan for the future.

- Phronetic: focusing on thematic and temporal approaches alone often lack an explicitly critical perspective on metropolitan change. A phronetic approach is essential for developing a rigorous understanding of what should be done, and how relations of power and values must be challenged to achieve alternative metropolitan futures.

Assembled together, the three-dimensional TTP framework offers a new approach to comparative research. Our approach starts from a position where the emphasis on comparison is not on differentiation, diversity and divergence but integration, inclusivity and interconnection. Whereas the former renders our understanding of the metropolitan reality more complex, we start with a recognition that understandings of metropolitan regions today are already so hyper-complex that rather than adding more complexity we must attend to more urgent and fundamental agendas. For our part these fundamental questions require a meso-level approach where the emphasis is on generalised aspects of concrete empirical realities. The meso-level is where the TTP framework is positioned within the broader contours of intellectual academic debates, but also the practice of influencing the planning and governance of metropolitan regions towards more progressive metropolitan futures. We illustrate this in Figure 14.1.

Fig. 14.1 Approaching metropolitan regions

Figure 14.1 does not deny the importance or come at the expense of macrolevel theoretical generality or micro-level empirical specificity, rather it shifts attention away from making metropolitan realities seem ever more complex but without over-simplification (cf. Paasi 2008). By placing the TTP framework at the meso-level our aim is to create a new space for engagement, one which can forge new ground in the debate over metropolitan regions, and more important, metropolitan regional futures. Occupying this space is not only planning and governance, but other domains too. We are only too aware, in the first instance, that our focus on planning and governance is arguably part of a larger political domain. The four dimensions we identify and mobilise in this book are not exhaustive, nor are they prescriptive or descriptive of the 'metropolitan reality' and political will of metropolitan regions. Others may identify other key drivers of metropolitan change from a political, planning, governance perspective. And secondly, the political domain planning and governance sit is not the only domain influencing met- 
ropolitan regional development. The TTP framework mobilised here in relation to planning and governance could be easily reproduced in other domains. Here we identify three other domains - economic, sociospatial, environmental \& health and associated themes for which the TTP framework could be applied. Again, this is illustrative, highlighting the potential to extend the approach adopted in this book.

\subsection{Metropolitan Futures: What Role for Planning?}

Set against this context, what can we identify as positive and proactive ways forward for metropolitan futures and a role for planning in metropolitan regions? Following the framework of the book, we focus on unpacking the four sets of issues that seem highly relevant to both shape future styles of governance and planning, and also provide metropolitan regions with modes of working that could make a difference. These are: (1) institutional make-up; (2) policy ideas; (3) spatial imaginaries; and (4) planning pathways.

\section{Institutional Make-up}

As we have seen in the examples discussed in this volume, institutions are finding that it is becoming more difficult to unilaterally shape the future of their cities and regions. This inability to respond relates to the need to understand and come to terms with the complex global forces and supranational drivers of change that are too fast paced to be dealt with through traditional and formal modes of government and governance. The clunky and sectored policy processes, that previously could be relied upon to coordinate some semblance of change, are fragmented and unwieldy. Alongside formal elected forms of representative government, we have seen the development of shadow governance processes comprised of other types of institutions forging partnerships with and between elected government and other agencies.

More recently, the twin-track processes of government and governance have been accompanied by a growing tendency to forge and utilise intermediate organisations that are sufficiently ad hoc and agile for agencies to be able to respond to issues at a proactive pace. Such intermediate organisations circumvent traditional modes of representative government and even governance partnerships but rely on the latter's legitimacy to function. Notwithstanding concerns over the transparency and constitutional status of such intermediate arrangements, there does appear to be some benefit of utilising a mixed mode of governance in individual cities for specific purposes. Our first requirement, therefore, is to recognise that metropolitan regions can display at least three different types of institutional processes and 
that these types can co-exist with each other in individual places. Adopting a diffuse institutional arrangement offers a more flexible form of governance responsiveness to address unique sets of issues prevalent within a metropolitan region. But it also means that the lines of democratic accountability and the formalised process of urban planning become much more diverse. We may lament about the degree to which past or existing forms of metropolitan planning are being compromised or replaced in this context, but we should also recognise that it is possible to adapt and renew to changing and more challenging sets of circumstances.

Metropolitan cities need to adapt and innovate to succeed globally, but also address the needs of their own cities and localities, and the citizens and businesses within them. This innovation, by its very nature, will require different forms of working to those that have existed up until recently. Among the new forms would be establishing:

(1) new modes of operating

(2) different types of partnerships

(3) new testing beds to trial projects, services and ideas

(4) new legitimacy for initiators that might be outside traditional institutions of power.

All of these new metropolitan institutional forms have their own challenges in formulation, legitimation, implementation and resourcing when compared to how we traditional govern and plan, and for some cities these challenges will make or sometimes break elected government. Transition will not be easy and there may well be resistance from those who have benefited from existing modes of government and the power structures that have been established. But equally there will be a wealth of opportunity to 'others' in the metropolitan arena to be freed up to think and act creatively and become part of a new landscape of adaptive and agile governance.

Shrewder political leaders are likely to see this adaptive and agile mode as a set of initiatives that can be seen to be revitalising metropolitan institutions. They can contribute to reawakening democratic and political involvement, reforming and updating government institutions, while celebrating and of course protecting their established sets of power. For less enlightened political leaders or at least those compromised by a system of power structures that are intended to inhibit strong leadership, a new reforming set of adaptive and agile arrangements are likely to be seen as a threat. This would be seen as a challenge to not only their own hold on power but also to the very institutions by which they and their interests were elected in the first place and are able to retain control over the various aspects of metropolitan politics.

The key determinants in shaping metropolitan governance and the institutions of power are likely to revolve around who shapes the innovation agenda in future. Where is the ability and who has the authority to initiate urban innovation projects led or championed by consortia of interests in order to address fundamental issues of concern and relevance to that city? Where are the flexible spaces within the institutions of metropolitan government and metropolitan planning that creates 
the ability for others, the non governing elite, to initiate change on their terms and develop innovative responses that are not constrained or at least held back by formal tiers of government and formal planning arrangements? To what extent can metropolitan regions permit or even create a co-existing multitude of government, governance and intermediate institutional forms? Will such institutional flexibility allow the availability of ad hoc flexible governance processes that draws state, business and community together to shape or places in the interests of the city as a whole?

\section{Policy Ideas}

Alongside a much more adaptive and agile form of governance and institutional arrangements, there will be a need to find new routes to shape and deliver policy through projects relevant to individual metropolitan regions. The twentieth century planning mode tended to fixate on a conventional survey-analysis-planimplementation loop within elected forms of government. This has been accompanied with opportunities to initiate public engagement at set times within the loop and to invite the business and development communities into the process when the market has the ability to respond and give meaning and action to planning intent.

A fault of this conventional approach has been treating the elected government as an all-encompassing entity that decides upon the required trajectory of the place, determines the timing of intervention and controls development opportunities. In other words, the hallmark has been that the state takes on the appearance of the proactive agent and reduces the market to reactivity. In older forms of planning across Western Europe, the state did indeed possess both the democratic mandate to select and initiate options for change, advertise intent to act within a plan and then resource that intervention through a series of public projects. But this approach is no longer a model that fits with how twenty first century European cities are witnessing physical change, even if the model remains relevant to more state-centric nations such as cities in China, Singapore and Arab states. Even those nations with defined constitutional and federal structures of government, and therefore greater discretion at their disposal, the ability of the state alone to initiate and deliver planning responses is no longer a linear path.

Where the state is no longer an all-pervasive force coordinating and controlling cities through total government and total planning, and increasingly relies on the market to initiate and deliver physical change, the conventional planning cycle is somewhat archaic. Developers no longer wait for the full cycle of plan preparation to be finished before seeking out land opportunities. Communities and members of the public resent having to wait set times for public consultation to express a voice in processes of urban and regional change. If the market identifies a business opportunity for intervention, they will want to press on ahead irrespective of the need to wait for the full circle of planning to be completed. This undermines the legiti- 
macy of having a plan in the first place, of course. It has also led some politicians to criticise planning for its delaying tendency and for the time it takes planners to complete and adopt a plan for a city.

But there are also merits in retaining a plan as an intelligence and synoptic force with political will, as a sum of the parts combining trends, analysis, foresight, public input and a long-term perspective. So, the key determinants in forging a future form of metropolitan planning is one where policy reflects political intent, but where the responses for particular parts of the city reflects the divergent interests who may want to develop or build or enact them.

Such a dilemma suggests ensuring a distinction between broad strategic spatial planning intent through policy statements and then a suite of different pathways for outcomes and delivery that reflect a diverse range of implementation agencies. There would still be a need for an overarching strategy for the entire city that takes time to prepare and takes on the form of a strategy of strategies. This strategy would need to reflect global and national intent as well as subnational drivers of change. This might be associated with a four-year political term of office (the strategy changes as city leaders change) and it may not be a physical plan but rather a suite of intelligence and data that sit alongside the political objectives. This may even be a publicly accessible online resource that is updated automatically from urban observation and intelligence sources. The broad policy intent and the updated intelligence reflecting ongoing metropolitan trends would keep the strategy relevant to changing circumstances. But instead of relying on a single allencompassing plan that gradually becomes more out of date and irrelevant as time passes, the translation into action and intervention could be achieved through various policy mechanisms that are more short term, customised in design and collaborative in ownership within the four-year cycle.

For such a transition to occur, political leaders would need to develop a candidate future metropolitan strategy for action as part of their political election campaigns that reflected broader national agendas in addition to their manifesto commitments. Translating these into actionable policy tools, from site-specific project briefs to infrastructure plans, would be a task for the institutions of government working with business, community and other delivery partners. The benefit would be holding politicians to a four-year strategy where they become the metropolitan animateurs while recognising that a broader spectrum of other actors, working together, will be required to implement policy ideas into delivery form.

\section{Spatial Imaginaries}

As we discussed earlier in the chapter, one hallmark of planning for well over a century has been its reliance on the visual. The plan, a schematic or land-use map or development zone illustration, has been a feature of planning since its modern development in the early twentieth century. For many nations and regions, the il- 
lustrative plan remains an important statutory means to communicate urban change and proposed futures. But the form that visualisation takes, a two dimensional (2D) perspective, has not changed much over that time. And yet we are in the midst of a digital revolution where imagery in the form of photography, motion picture, animation, video and meme are being used increasingly day-to-day to record places, mobility and change. This technology extends the art of the possible in terms of capturing urban and regional change, projecting places to broader audiences and providing the tools to recreate the past and hypothesise the future. It also democratises urban and regional visualisation, since everyone armed with a smartphone (about half the world at present) - professional novice alike - is now able to make their own images, upload them to online platforms and social media instantly, and provide powerful messages about change in visual form. Everyone is now able to create a spatial imaginary of a place.

The 2D plans of cities remain of relevance and of interest to professionals, geographers and historians among others. But they seem somewhat archaic in the context of video, 3D videos, digital animation and hyperlapse photography used by designers and architects. Given the immense interest in visualisation, could metropolitan planning adopt new methods that embrace a broader spectrum of illustrative devices, partly to communicate the possibility of urban change but also to reawaken an interest in the public in engaging with ideas about the future of cities?

We often forget that before the introduction of city plans more regularly and formally in the middle of the twentieth century, cities across Europe embarked on much more innovative means of engaging citizens with grand plans for urban change. As Rob Freestone and Marco Amati (2014) have showed, these include the use of city museums and city exhibitions, first promoted by Patrick Geddes in the early 1900s, and the high use of documentary film between the 1930s and 1960s.

Somewhere in the latter quarter of the twentieth century, planners forgot how to engage audiences in more exciting visual ways as film, exhibition and photography died away in favour of 2D representations. Developers have made an effort of course, glamorising new developments through artistic renderings of attractive lifestyle choice new homes and happy sunny retail spaces for urban centres; the imagery has changed here, moving from hand drawn images of prospective futures to digital altered photographs of real places, photoshopped with new buildings and even people. Some cities have gone further (Helsinki, Canberra, Edinburgh, Singapore for example), embarking on city vision exercises that positively embrace more creative methods, while other cities (Hong Kong, Shanghai, London, Chicago, for example, but with varying motives) have blown the dust off the idea of city exhibitions and devised pop-up urban room exhibitions and city models as devices to get citizens and investors talking about metropolitan change. And yet many of these innovations are just that because they remain the exception to the rule in more metropolitan planning processes. 
We would argue that it is increasingly important to be seen to adopt new technologically advanced forms of spatial imaginaries to accompany all forms of present and future planning activities on a city-wide basis in metropolitan regions. Not only would this reflect the overwhelmingly positive appetite on the part of citizens and travellers to record the urban though digital imagery, it would also provide a much needed more open style of participatory engagement about city futures.

The key determinants in adopting enhanced forms of city visualisation is allowing anyone with an interest in a place to share their perspectives of cities in ways they can control and communicate with broader audiences. But it would be necessary for this visualisation to become part of the broader metropolitan planning process, where professionals listen and view a citizen's perspective of the urban together with their likes and dislikes, represented in visual form. Pilot exercises run in Newcastle upon Tyne indicate a positive take-up of new digital photographic, video and drawing media in addressing the long-term future of the city, often led by children and young people that, in turn, attract the attention of parents, grandparents and other family members and friends (Tewdwr-Jones et al., 2019). The challenge would be to convince professional planners to see the knowledge gathering, idea generating merits of more visual means that could inform their hitherto closed and predominantly written communication devices. Translating imagery into a planning and institutional context would require some skilled treatment (visual ideas do not have to be nested within any plan but rather inform and shape it in multiple ways). But the use of places where there was an open multimedia dialogue would at least be the first step at revising a spatial imagination of the metropolitan while generating more open forms of engagement.

\section{Planning Pathways}

There is a real danger that planning will increasingly be seen as an archaic twentieth century top-down state activity, detached from the complex drivers of change affecting cities, remote from the requirements of the digital and global age, and irrelevant to modern processes of citizen engagement. If planning is going to serve a purpose in the twenty first century, it must adapt to survive. Metropolitan planning could become a more adaptive and agile suite of methods and processes that addresses some of our more challenging conditions, celebrates diverse urban voices, embraces creative and digital techniques that engage and inspire, and responds to social need, environmental change and economic growth. The status quo is not an option. But the task of transforming metropolitan planning is no easy task, when so many conservative forces and vested interests are apparent, not least among those who were responsible for promoting current and increasingly historic forms of planning. 
A one-size fits-all approach to planning even within a single nation across an array of metropolitan regions appears to be an obsolete perspective. The implications of adopting a multiple perspective of planning, essentially planning plural, are obvious; not only does metropolitan planning become more aligned to the changing interests of individual cities and potentially more responsive to citizens and businesses within the city, but it also challenges the state's grip over planning. The enduring form of planning rests not with particular types of plans that have been extant for decades or even with those who historically control urban agendas. The enduring form of planning rests on the components of planning, its ability to be agile and responsive, its attempt to encompass diverse views and mediate between competing agendas, and its ministry to secure legitimacy and commitment for a long-term view of a city's future. As John Forester (2009) has noted, planning's position in managing change is, and should be, a story of hope.

While metropolitan planning requires a synoptic and strategic perspective, we should not think that the problems of the urban as a whole can be resolved by automated systems thinking. Bryan McLoughlin's (1969) contribution to the changing condition of cities in the 1960s by advocating a systems view of planning was important in addressing both the challenges and opportunities of the modelling age. But we have learned a great deal in the last 50 years of not to see systems thinking through computing techniques as the only means by which we try and resolve urban problems. As we enter another period of cities as dynamic digital platforms hosting novels forms of smart data, we should not believe that digitisation is the only way to plan and police the metropolitan, and politicians should not be hoodwinked into thinking that they can truly address problems by handing over city assets to large digital corporations divorced from the place. There is a place for digital and data in future metropolitan cities, but only where it can be harnessed to achieve citizen and community advantage, and where it helps overcome deep-seated urban problems.

Planning outlives a legislatively fixed view of planning and, in so doing, creates pathways for change that can absorb new demands and new sets of urban actors. It is, and must be viewed as, a long-term game. And when allied to particular places, with all their unique histories, geographies, place memories, identity and past forms of political and planning interventions, they can take on an inherent power. The infrastructure of cities acts as sunk costs. Airport, port, highways, rail and metro lines and stations, energy sources, power plants, even universities and hospitals, already exists and therefore as hubs can shape and dictate the future urban canvas. This includes temporal moves to radically respond to urban challenges by designating out-of- or edge-of-centre urban employment zones, science parks and retail centre.

Sometimes infrastructure assets do not meet the changing needs of cities; on other times they create economic and social externalities. In all cases, there is a role for strategic spatial planning not necessarily in institutionally and politically capturing infrastructure decisions and funding, but rather in addressing issues of wider metropolitan embeddedness to address economic unevenness, real estate 
price bubbles and mobility congestion. Planning can also consider the knock-on effects of infrastructure investment to wider social needs and service provision, including schools, health centres, telecoms and waste management, before stresses and strains happen. There is a case for seeing planning's relationship to infrastructure as an opportunity means to avoid significant costs for cities over time if the impacts are assessed early enough.

Of course, some new ideas for how to manage metropolitan regions are, in point of fact, hardly new at all. As both Vanessa Watson (2016) and Peter Hall (2014) have remarked, old ideas tend to resurface occasionally because, in essence, they remain relevant for the specific planning needs of those places. The likelihood of those ideas being adopted and implemented, however, are largely dependent on contextual forces, stemming from political commitment, public appetite, investor perspectives and - perhaps above all - time.

For every form of planning intervention, there will be a need to address the resultant externalities and intervene again at some point in the future, and that cycle is not an excuse not to enact forms of metropolitan planning at all. But with changing societal expectations, a global economy, a search for place distinctiveness, coupled with older and dated forms of existing planning techniques, there is a case for challenging the forms of metropolitan government and planning we have become all too used to. Future metropolitan planning might not be seen solely through a single plan, it might not be the responsibility of metropolitan government, and it might not be there only to serve development interests. It might become a repository of public-facing second-by-second urban intelligence, it might comprise a diverse set of tools and digital platforms, and it might act as a facilitation platform for new ideas and innovations that citizens, communities and businesses can contribute to. Twentieth century metropolitan planning is defunct; we should get used to it.

\subsection{Metropolitan Regions, Planning and Governance: What Next, Where Next?}

Besides the general agreement that metropolitan regions are of relevance, the debate remains somehow inconclusive as regards what form metropolitan planning and governance should take going forward. At one level, we continue to appear surprised (though by now we surely cannot be?) by the emergence of new 'in vogue' ideas and mantras on the form metropolitan planning and governance must take - smart, networked, resilient, creative, sustainable, competitive, city-regional, megaregional - that quickly take on a globalised form and seemingly selfperpetuate towards and during a period of political-economic orthodoxy. The problem here is we cannot negate that there is a polemic undertone (in the sense of stylised controversies) and it is often difficult to equate this with the national and region specific-forms each takes on in practice. At another level, there is the 
piecemeal landscape of metropolitan activities and region-building which emerge in a specific place, at a specific time, often as a side-effect, unintended coincidence or entirely by accident. In each scenario, issues of comparability emerge.

In this book we have argued for a more open, broader perspective on metropolitan regions. We have advanced the TTP framework as providing one analytical tool through which this might be enabled. In this final section we conclude with three more open propositions relating to thematic, temporal and phronetic priorities:

- What questions should we be asking? For us it is less important to be asking: What the (next) institution, policy idea, imaginary or planning style is or should be? These are important questions but they are only a first step. Far more important are the questions: Who are institutions, policy ideas, imaginaries or planning styles for? How and why are they originating? What is at stake for those included and excluded? What are the implications for different places and parts of society?

- Where should we be looking? Much of the work on metropolitan regions has been dominated by research in and of Western Europe and North America, and written for a predominantly Western European and North American audience. It is clear that a 'Southern' turn is taking place currently, but this should not be at the expense of, but rather complementary to, Northern perspectives. Writing from a European perspective, our aim in this book has been to develop and operationalise a framework which could be applied as a heuristic device to engender dialogue across contexts and cultures. In short, our meso-level approach aims to develop a shared set of thematic and phronetic priorities around which we can look to engage in more interdisciplinary and cross-contextual conversations. We have also been keen to stress the need to adopt and pursue more historical, periodised, approaches such that we contextualise current developments and activities within the broader contours of metropolitanisation processes.

- What is the bigger picture? Our final aim has been to situate metropolitan regions, change and development within a broader political-economy. It goes without saying that we have been necessarily selective in what we can set out to achieve in the pages of the book, but the emphasis throughout has been outward rather than inward looking. On the one hand, we have been keen to emphasise the need to be outward looking within accounts of metropolitan regionalism, acknowledging internal diversity in disciplinary approaches, tools and cases. On the other hand, we have endeavoured to show examples of how we need to be outward looking beyond accounts of metropolitan regionalism per se, recognising that metropolitan regions are one among many spatial concepts. Moreover, what happens in relation to metropolitan regions is one thing, while it is entirely another to see how that complements, contradicts, overlaps, competes with other processes that act in, through or on these spaces.

When all this has been said and done, we aim to have convinced you, the reader, never to assume that metropolitan regions are the (only) answer. Often it can be 
easy to assume they are. But if planning and governing metropolitan regions is to continue providing answers to twenty-first century problems, perhaps the starting point should be to ask: if metropolitan regions are the answer, what question is being asked?

\section{References}

Ammann, C. \& Förster, T. (Eds.) (2019). African Cities and the Development Conundrum. Leiden: Brill Open.

Barber, B. (2013). If Mayors Ruled the World: Dysfunctional Nations, Rising Cities. New Haven, CT: Yale University Press.

Borraz, O., \& Le Galès, P. (2010). Urban governance in Europe: the government of what? Pôle Sud, 32(1), 137-151.

Davidson, M. \& Ward, K. (Eds.) (2018). Cities Under Austerity: Restructuring the US Metropolis. Albany, NY: SUNY Press.

Etherington, D. \& Jones, M. (2016). The city-region chimera: the political economy of metagovernance failure in Britain. Cambridge Journal of Regions, Economy and Society, 9(2), 371-389.

Fiddian-Qasmiyeh, E. \& Daley, P. (Eds.) (2019). Routledge Handbook of South-South Relations. Abingdon: Routledge.

Forester, J. (2009). Dealing with Differences: Dramas of Mediating Public Disputes. Oxford: Oxford University Press.

Freestone, R. \& Amati, M. (Eds.) (2014). Exhibitions and the Development of Modern Planning Culture. London: Ashgate.

Friedmann, J. \& Sorensen, A. (2019). City unbound: emerging mega-conurbations in Asia. International Planning Studies, 24(1), 1-12.

Galland, D. \& Elinbaum, P. (2018). A 'field' under construction: the state of planning in Latin America and the southern turn in planning. dis $P$ - The Planning Review, 54(1), 18-54.

Galland, D. \& Harrison, J. (2020). Conceptualising metropolitan regions: how institutions, policies, spatial imaginaries and planning are influencing metropolitan development. In K. Zimmermann, D. Galland \& J. Harrison (Eds), Metropolitan Regions, Planning and Governance (pp. xxx-xxx). Berlin: Springer.

Gross, J.S., Gualini, E. \& Ye, L. (2019). Constructing Metropolitan Space. Actors, Policies and Processes of Rescaling Metropolises. Abingdon: Routledge.

Hall, P. (2014). Cities of Tomorrow: An Intellectual History of Urban Planning and Design Since 1880 (4th edition). Chichester: Wiley-Blackwell.

Harrison, J., Fedeli, V. \& Feiertag, P. (2020). Imagining the evolving spatiality of metropolitan regions. In K. Zimmermann, D. Galland \& J. Harrison (Eds), Metropolitan Regions, Planning and Governance (pp. xxx-xxx). Berlin: Springer.

Jones, M. (2019). Cities and Regions in Crisis: The Political Economy of Sub-National Economic Development. Cheltenham: Edward Elgar.

Katz, B. \& Bradley, J. (2013). The Metropolitan Revolution: How Cities and Metros are Fixing our Broken Politics and Fragile Economy. New York: Brookings Institution Press.

Kovacic, Z. (2019). Governing informality through representation: examples from slum policies in Brazil and South Africa, Cities DOI: 10.1016/j.cities.2018.07.009

Lawhon, M., Silver, J., Ernstson, H. \& Pierce, J. (2016). Unlearning (un)located ideas in the provincialization of urban theory. Regional Studies, 50(9), 1611-1622.

McLoughlin, J.B. (1969). Urban and Regional Planning: A Systems Approach. London: Faber and Faber. 
OECD (2015a). The Metropolitan Century. Understanding Urbanisation and its Consequences. Paris: OECD Publishing.

OECD (2015b). Governing the City. Paris: OECD Publishing.

Oosterlynck, S., Beeckmans, L., Bassens, D., Derudder, B., Segaert, B. \& Braeckmans, L. (Eds.) (2019). The City as a Global Political Actor. Abingdon: Routledge.

Paasi, A. (2008). Is the world more complex than our theories of it? TPSN and the perpetual challenge of conceptualization. Environment and Planning D: Society and Space, 26(3), 405410 .

Peck, J. (2016). Economic rationality meets celebrity urbanology: exploring Edward Glaeser's city. International Journal of Urban and Regional Research, 40(1), 1-30.

Peck, J. (2017a). Transatlantic city, part 1: Conjunctural urbanism. Urban Studies, 54(1), 4-30.

Peck, J. (2017b). Transatlantic city, part 2: Late entrepreneurialism. Urban Studies, 54(2), $327-$ 363.

Rodríguez-Pose, A. (2018). The revenge of the places that don't matter (and what to do about it). Cambridge Journal of Regions, Economy and Society, 11(1), 189-209.

Stone, D. (2008). Global public policy, transnational policy communities, and their networks, Policy Studies Journal, 36(1), 19-38.

Tewdwr-Jones, M., Sookhoo, D. \& Freestone, R. (2019). From Geddes' city museum to Farrell's urban room: past, present, and future at the Newcastle City Futures exhibition. Planning Perspectives DOI: 10.1080/02665433.2019.1570475

Tomlinson, R. \& Harrison, P. (2018). Knowledge of metropolitan governance in the South. International Journal of Urban and Regional Research, 42(6), 1127-1139.

Watson, V. (2016). Locating planning in the New Urban Agenda of the urban sustainable development goal. Planning Theory, 15(4), 435-448.

Wheeler, S. (2015). Five reasons why megaregional planning works against sustainability. In Harrison, J. \& Hoyler, M. (Eds.), Megaregions: Globalization's New Urban Form? (pp. 97118). Cheltenham: Edward Elgar. 


\section{MACRO-LEVEL}

Emphasis is on producing broad conceptualanalytical

frameworks; focuses on theoretical generality across time and space

\section{MESO-LEVEL}

Emphasis is on generalised aspects of concrete, empirical developments; focus is on specific dimensions be they thematic, temporal, phronetic.

\section{MICRO-LEVEL}

Emphasis is on systematic comparative approaches; focus is on looking for differences across time and space focusing on diverse empirical cases

\section{Globalisation}

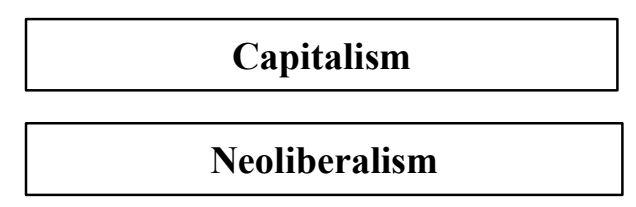

\begin{tabular}{|l|}
\hline Democratisation \\
\hline Decentralisation \\
\hline
\end{tabular}

Urbanisation

Financialisation

\section{Rescaling}

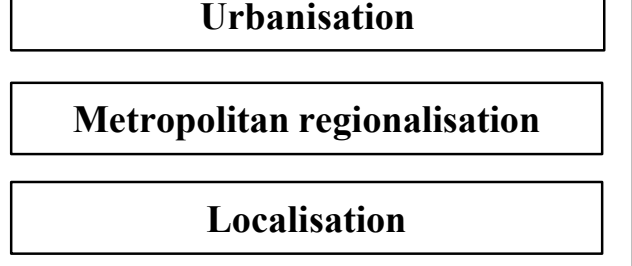

(
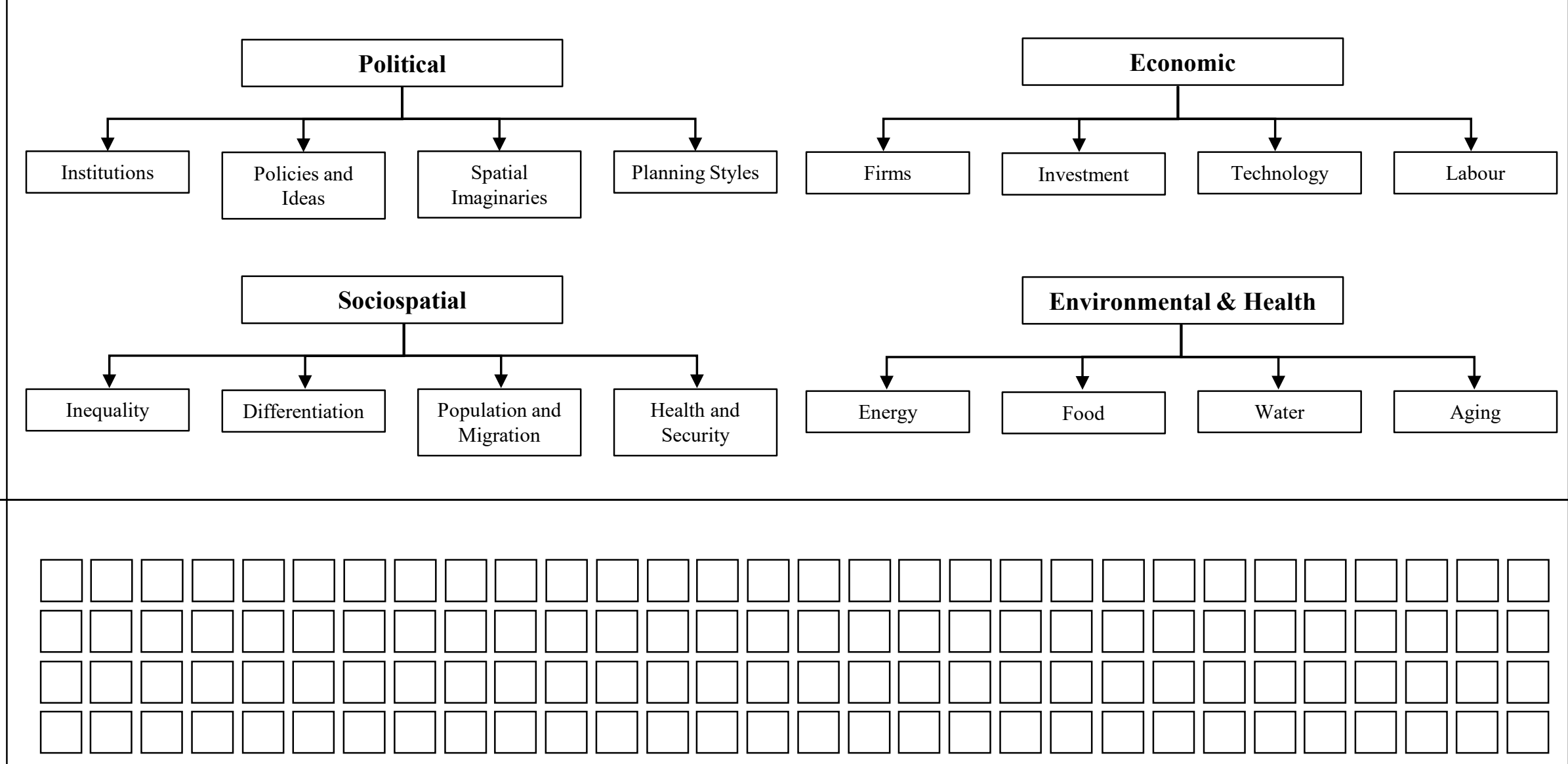